\title{
CONTENT CONSUMPTION ON THE INTERNET AMONG HIGHER EDUCATION STUDENTS - PRELIMINARY RESULTS OF A PROJECT AT A HIGHER EDUCATION SCHOOL IN PORTUGAL
}

\author{
Sónia Ferreira ${ }^{1 *}$, Salomé Morais ${ }^{2}$, Teresa Gouveia ${ }^{3}$, Filomena Sobral ${ }^{4}$, Cristina \\ Gomes $^{5}$ \\ ${ }^{1}$ Prof. Dr., Escola Superior de Educação, Centro de Estudos em Educação, Tecnologias e Saúde, \\ Instituto Politécnico de Viseu, PORTUGAL, sonia.ferreira@esev.ipv.pt \\ ${ }^{2}$ Prof. Dr., Escola Superior de Educação, Centro de Estudos em Educação, Tecnologias e Saúde, \\ Instituto Politécnico de Viseu, PORTUGAL, salome@esev.ipv.pt \\ ${ }^{3}$ Prof. Dr., Escola Superior de Educação, Centro de Estudos em Educação, Tecnologias e Saúde, \\ Instituto Politécnico de Viseu, PORTUGAL, tgouveia@esev.ipv.pt \\ ${ }^{4}$ Prof. Dr., Escola Superior de Educação, Centro de Estudos em Educação, Tecnologias e Saúde, \\ Instituto Politécnico de Viseu, Centro de Investigação em Ciência e Tecnologia das Artes, \\ PORTUGAL, filomena@esev.ipv.pt \\ ${ }^{5}$ Prof. Dr., Escola Superior de Educação, Centro de Estudos em Educação, Tecnologias e Saúde, \\ Instituto Politécnico de Viseu, PORTUGAL, mcagomes@esev.ipv.pt \\ ${ }^{*}$ Correspondig author
}

\begin{abstract}
The global increasing importance of the Internet in the various segments of society is explicit, and its rapid control by younger users particularly seems irrefutable. But what do they consume? This paper presents the partial and preliminary results of the Project - The consumption and sharing contents of Internet by students of higher education: the case of the Polytechnic Institute of Viseu, Portugal, specifically related to the consumption practices of Internet content by students of the School of Education, one of the Polytechnic Institute of Viseu Schools. The principal objective of the Project is to understand the use that higher education students do of the contents available on the Internet.

The methodological approach includes the application of an online questionnaire survey, with questions related to: i) the socio-demographic and institutional data of the participants; ii) access to and use of the Internet; iii) competences for its use; iv) consumption and sharing content; v) and attitudes and preferences regarding consumption and sharing.

The sample includes 120 students, with participation of students attending the courses of Social Communication $(\mathrm{N}=79)$ and Multimedia and Plastics Arts $(\mathrm{N}=32)$. Most of the participants are female $(\mathrm{N}=88)$, attend the 1 st year of the course $(\mathrm{N}=88)$ and the average age is 19.36 years $(\mathrm{SD}=2.56)$. Asked about how often they access the Internet, $95.8 \%$ of the students said they use it every day.
\end{abstract}

Preliminary results from the quantitative analysis suggest that the most popular activities are: listen to music, see photos and read text posts on social networks daily.

The analysis presented in this article refers only to data obtained between June and September 2017 and was performed using the SPSS - Statistical Package for Social Sciences.

Keywords: Higher Education, Students, Internet, Consumption. 


\section{INTRODUCTION}

All over the world statistics show the unquestioned penetration and constant use of Internet. Currently, and in this age generations of future adults grow up surrounded by the whole array of technological possibilities and their way of being, thinking, feeling and acting is often conditioned by living online. Later, young netizens are fully familiar with technology and the Internet, making them the centre of their lives. They develop different skills and abilities different from earlier generations and can perform various tasks and roles at the same time. Their world is simultaneously real, virtual, interactive and fast-tracked. They have been brought up in the digital age and their culture is strongly determined by the day-to-day presence of the media, social networks and socialization through the Internet. In addition to this, their perception about the presence and use of the web is positive, mainly highlighting its characteristics of enjoyment, rather than those of danger or safety.

Equally important is the fact that the current perspective of using the virtual universe is guided not only by personal interests, but also conditioned by friendships or membership groups. They have "moving minds" (Cardoso, Espanha, \& Lapa, 2009, 118), of fast-moving multimedia reasoning and arise in a technologically advanced world where immediacy, control, speed, movement, invention and innovation are keywords.

In fact, the network society paved the way for a hybridity that has made it easier to communicate and provides simultaneity. The reality of cyberspace has reduced distances and time. The village is now truly global and self-media are the key players. A culture of participation and the touch experience provided by screens are highlighted. The use and supply are immediate, and there is an increasing desire to know not only the identity profiles, but also what young people are consuming and sharing.

In this sense, there is a rising concern on the part of national and international studies to understand online behavior. Thus, it is the objective of this study to understand, in a substantiated way, how young people use the Internet, what their goals and aspirations are, and what routines they have when it comes to the use and communication of Internet. Therefore, the present text begins by focusing on the online culture that guides the current experience of the youngest, and then emphasizes the presentation of the research project CI\&DETS 0014, revealing the preliminary results obtained to what concerns the higher education participants of the School of Education (ESEV), and ending with a critical reflection.

\section{THE ONLINE CULTURE}

In nowadays world, we have become accustomed to living with the Internet, not only at the beginning of the new millennium, but already within the last years of the previous century. New patterns of human behavior are surfacing, especially among those who were born in the midst of technology. These youngsters, who communicate to the world from their bedroom, regularly access the Internet in a variety of places, including school and leisure areas, handle various devices and initiate innumerable online activities. Not only do they dominate the inherent literacy of interaction platforms, but they also apply new processes of literacy in the ways of communication they develop.

Referred to as Gen Y or Millennials (Bracy, Bevill, \& Roach, 2010), these generations have never met the "street culture" (Cardoso, Espanha, \& Lapa, 2009, 10), but "have been raised in the midst of changes in the domain of communication interactivity and among a system of multiple manufacturers and distributors" (Cardoso, Espanha, \& Lapa, 2009, 9). Indeed, the aforementioned authors point out that "new skills seem to be acquired intuitively by these younger individuals as the way to explore the interconnection between the several media realities and the way of operating numerous media files simultaneously" (Cardoso, Espanha, \& Lapa, 2009, 9). Their lifestyle is therefore moved by screens, both in a public and private scope, intuitive and multitasking. In a similar way, Ponte $(2016,2)$ points out that "The new generations are growing in conditions, which are very different from those that surrounded their parents, who in turn also experienced different childhoods from their parents." Very young children are given a smartphone to keep themselves entertained with music and games, in primary schools the tablets are part of the learning supports, and in the subsequent years of learning, computers have become a reality that culminate in the working universe with the crucial presence of the web. Surrounded by technological possibilities, societies slowly give into their charm. Elder people want to try them out; whereas for younger individuals, it is a natural environment. As emphasized by Cardoso, Espanha and Lapa $(2009,10)$ "Young people grow up in an environment that is saturated, where choices about what to do and what to experience seem to grow exponentially."

In recent times, the debasement of Internet use worldwide has been on the rise. According to Patrão and Sampaio (2016, XXIII), "The number of Internet users per 100 people has increased by $806 \%$ between 2000 and 2015" and they stress that "The mobile phone is the most used device to access the Internet rapidly, with an estimated 4.43 million users worldwide by 2015." One can even claim, by establishing an analogy with Macluhan (1964), that these days the mobile phone is the new extension of the human being. It is open 
to the world, in a reduced size, which you everlastingly carry with you, and allows you to permanently stay connected. Cardoso, Espanha e Lapa $(2009,89)$ point out that in addition to be an extension of the body, the mobile phone can also be assumed "as a neuralgic extension of one's personal and social self, serving as a mediator in a relationship with others along with the social world".

Pertaining to the reality in Portugal, according to the report of the Consumer of Electronic Communications 2015 of the National Communications Authority (ANACOM, 2016, 24), within the residential market, "the presence of the mobile phone service among people aged 10 or over reached 95 percent in the fourth quarter of 2015." Furthermore, according to the same report, by the end of 2015, "smartphone penetration reached 66.7 per cent among mobile phone users aged 10 or over". This number has been increasing in recent years, in which the largest increase took place in 2015 (+14.3 percentage points) (ANACOM, 2016, 39). What is more, "The majority of smartphone users belong to the 15 to 34 age gap and hold higher levels of education (secondary school level and higher education degrees)" (ANACOM, 2016, 40). It is also verified that the penetration of smartphones is greater among students (95\%). Recent data from the website Meios \& Publicidade (Durães, 2017, online) highlight that in March 2017, mobile phones accounted for $41 \%$ of website views in Portugal in the month in question. According to the information published, $59 \%$ of the audited traffic was generated by PC (desktops or laptops) and $41 \%$ by mobile equipment, among which smartphone access accounted for $35 \%$ of the monthly consumption whereas tablets were responsible for $6 \%$ of page views". The same source also says that, "When compared to the same month of the previous year, smartphones were the devices that acquired the most quota (11 percentage points), tablets took in a percentage point, while the PC lost 12 percentage points in the same period" (Durães, 2017, online).

In the same line of thought lies the data from the Internet World Stats report of March 25, 2017 (IWS, 2017), which corroborate that a great percentage of the global population has access to the Internet. As far as the regional percentage of the world is concerned, we can see that Asia alone holds $50.2 \%$ of Internet users, followed by the European continent with $17.1 \%$ of users and Latin America and the Caribbean with $10.3 \%$ of infonauts. With reference to the African region, 9.3\% access the Internet, followed by North America (8.6\%), the Middle East (3.8\%) and Oceania/Australia (0.7\%). In the Top 20 of the countries with the biggest number of Internet users, China leads the ranking, placing Germany in 9th place, with a population of "only" $80,636,124$. Within the scope of the Portuguese, "by the end of 2015, fixed broadband Internet access service (BLF) was available in 64 per cent of households. The diffusion of mobile broadband Internet access service (BLM) was 46 per cent among individuals aged 15 and over, and increased considerably in 2015 (+9.5 percentage points)" (ANACOM, 2016, 26). On the other hand, "The percentage of people who has never used the Internet access service has been decreasing, having reached 28 percent in 2015, 12 percentage points above the EU28 average" (ANACOM, 2016, 15). Still according to ANACOM $(2016,15)$, "These differences in respect of the EU are even more evident among older individuals (over 54 years old), with a low level of education (up to the 3rd cycle of basic education), retired and with lower incomes".

Accordingly, the results of the Survey on the Use of Information and Communication Technologies by Families, conducted in 2016 by the Portuguese National Statistics Institute (INE), show that $72 \%$ of users accessed the internet on mobility. That number was 35\% in 2012 with Internet usage rates of $98 \%$ among those with higher education. The same survey confirms that Internet use is prevalent among students and that mobile phones or smartphones (78\%) and laptops (73\%) are the most frequently referred to by Internet users to access this network. On the other hand, Ponte $(2016,2)$ shows that "among young Portuguese adults between 16 and 24 years old, internet access is nearly complete $(98 \%)$, falling into the succeeding age groups, but still reaching 59\% between 45 and 54, the age range of many of the children's and adolescents' parents." The author also highlights that "Portuguese Internet users over the age of 15 are the front-runners when it comes to the use of digital social networks within the European context. In $2014,70 \%$ used these networks, for an average of $57 \%$ in the 28 countries of the European Union" (Ponte, 2016, 2). Ponte also stresses that Facebook is the most popular social network in which $98 \%$ of Portuguese Internet users have a profile, and where sending messages is the most frequent activity (85\%). Additionally, continuing in the author's rationale, we realize that young Portuguese people love to "put" "likes" on other pages, use chats and comment publications (...); create photo albums and mark their friends' birthdays" (Ponte, 2016, 2). With regard to the consumption of online audio-visual content, the report "The new dynamics of audio-visual consumption in Portugal", by ERC (2016), states that this is a common activity with very expressive numbers on the part of individuals whose age ranges between 15 and 34 years old.

Therefore, the newer generations of Portuguese individuals spend a lot of time online to carry out diverse activities of communication, research, information, leisure or study, among others. On the topic of studying, it is known through research that young Portuguese adults "on average and per week, according to the level of education, spend 2 hours (basic level education), 6 hours (secondary level education) and 42 hours (higher education level) online to study" (Patrão \& Hubert, 2016, 98). This confirms that, they spend a lot of time 
studying. Thus, knowing that there are many perspectives in the online world, the benefits are commendable, but society is also increasingly confronted with questions whose answers do not yet exist. Everything is too fast and if the tracking pace of the young individuals is innate, researchers, parents and teachers try to understand to what extent the new generations use the Internet. Access to the World Wide Web is nowadays easy and direct among youngsters who, in turn, also have access to various types of gadgets to remain in the virtual world. In other words, the miniaturization of the devices, the increase in their performance potential and low prices have widespread their acquisition and possibility of these young individuals to have access to functionalities made available by multiple applications. As a result, it also increases "the time, the way and the environment in which they are online" (Almeida \& Gouveia, 2016, 75).

It is in this context that more and more studies seek to understand young individuals' use of the Internet, the technological means of access and the level of information literacy that it dominates, in addition to the manifestly important pursuit to find out about the content to which they have access to in the electronic world. The approaches to research are manifold and varied, but they usually display the need to add knowledge to the thematic scope in order to facilitate intergenerational dialogue and not leave young people inaccessible to a changing domain. Bearing in mind that "The new generations, which are called tech-savvy [...] or even virtual generation, add to their repertoire online behaviours. They communicate and relate to the network" (Patrão \& Hubert, 2016, 97), it is increasingly necessary to obtain data about young people's online preferences, as well as "to evaluate the role that online behaviour plays" (Patrão \& Hubert, 2016, 98). How do they think, act, and consume?

\section{BRIEF PRESENTATION OF THE PROJECT}

The project CI\&DETS 0014 - The consumption and sharing of content on the Internet among higher education students - the case of the Polytechnic Institute of Viseu - aims to identify what kind of content students consume and share online. It started on September 1st, 2016 and will continue until August 31st, 2018.

In general, the study aims to: i) identify the online content consumed by the students of the different schools of the IPV; ii) to understand the purposes and in which contexts the content is viewed and shared; iii) to identify the benefits and main problems of content consumption and sharing.

Methodologically, this is a case study, which favors the use of quantitative methods for the collection of data, namely the application of an online questionnaire survey, available at http://www.esev.ipv.pt/questionario/, from June 5th to September 30th, 2017. The dissemination was carried out via email to all the organic units of the Institute.

This data collection instrument is composed of a set of 21 closed-answer questions. It is used for: i) the sociodemographic and institutional characterization of the participants; ii) an enquiry of access and use of the Internet; iii) clarification about online consumption behaviors and content sharing; iv) understanding the attitudes and preferences regarding the consumption and sharing of contents. Aside from the first part of the questionnaire, we chose to use the Likert psychometric response scale. The results were quantitatively treated using the statistical analysis software SPSS - Statistical Package for Social Sciences.

It is expected that the overall results obtained will guide towards more informed decisions about the Institute's communication and information dissemination practices among its students, as well as being useful in developing strategies to attract new students and proposals from other study cycles.

\section{PRELIMINARY RESULTS}

\subsection{Participants}

A total of 120 students of ESEV (Table 1) participated, mostly female (73.3\%), aged 17-39 years, with the mean age being 19.36 years (Table 2).

Table 1 - Gender of participants

\begin{tabular}{|l|l|l|}
\hline & Frequency & Percentage \\
\hline Female & 88 & 73,3 \\
\hline Male & 32 & 26,7 \\
\hline Total & 120 & 100,0 \\
\hline
\end{tabular}




\begin{tabular}{|c|c|c|c|c|c|}
\hline & $\mathbf{N}$ & Minimum & Maximum & Mean & \begin{tabular}{|l|} 
Standard \\
Deviation
\end{tabular} \\
\hline Age & 120 & 17 & 39 & 19,36 & 2,56 \\
\hline
\end{tabular}

As for student status (table 3 ), practically all students referred to having an ordinary status $(96.7 \%)$ and the clear majority $(73.3 \%)$ were attending the $1^{\text {st }}$ year of higher education (table 4$)$.

Table 3 - Student Status ${ }^{1}$

\begin{tabular}{|l|l|l|}
\hline & Frequency & Percentage \\
\hline Ordinary student & 116 & 96,7 \\
\hline Working student & 2 & 1,7 \\
\hline Other & 2 & 1,7 \\
\hline Total & 120 & 100,0 \\
\hline
\end{tabular}

Table 4 - Academic Year Student is attending

\begin{tabular}{|l|l|l|}
\hline & Frequency & Percentage \\
\hline $\mathbf{1}^{\text {st }}$ year & 88 & 73,3 \\
\hline $\mathbf{2}^{\text {nd }}$ year & 32 & 26,7 \\
\hline Total & 120 & 100,0 \\
\hline
\end{tabular}

\subsection{Online Content Consumption}

The results show that a very high percentage $(95.8 \%)$ of students say that they access the Internet every day, followed by a very small number of participants who said that they only accessed it some times per week (1.7) and some times per month (1.7) (Table 5)

Table 5 - Frequency of accessing the Internet

Table 5 - Frequency of accessing the Internet
Frequency
\begin{tabular}{|l|l|l|l|}
\hline Percentage & $\begin{array}{l}\text { Valid } \\
\text { Percentage }\end{array}$ \\
\hline Some times per month & 2 & 1,8 & 1,8 \\
\hline Some times per week & 2 & 1,8 & 1,8 \\
\hline Every day & 106 & 95,5 & 96,4 \\
\hline Total & 110 & 99,1 & 100,0 \\
\hline Lacking & 1 &, 9 & \\
\hline Total & 111 & 100,0 & \\
\hline
\end{tabular}

Concerning the most consumed content (Table 6), students' preferences indicate that they listen to music $(59.2 \%)$, view photographs $(49.2 \%)$ and check posts on social networks $(48.3 \%)$ on the Internet every day. Entertainment content in audio format (42.5\%) and memes (33.3\%) are also among students' daily consumption habits.

Video content, namely films/series/documentaries (52.5\%) and information (50.0\%) are consumed some times a week by most respondents. The results show that students consume, on a weekly basis, video format content on the Internet, such as:

- Video clips (45.8\%);

- Comedy sketches (42.5\%);

\footnotetext{
${ }^{1}$ In Portugal, students who hold a job contract may enrol as working students and have access to specific exceptions in each HEl's academic regulation such as: not attending classes and opting for final exams instead of mid-term exams. Students who do not enrol as working students are considered ordinary students and do not share the same exceptions defined in the HEl's academic regulation for working students.
} 
- Short animations $(36.7 \%)$;

- Advertisement (30.0\%).

Checking information (news articles/ opinion articles/ etc.) in textual format is indicated as an activity performed a few times per week by $41.7 \%$ of the students.

In turn, $37.5 \%$ of respondents also reported consuming informational content in audio format some times a week. Comparing these results with those presented previously, it allows us to conclude that the students express a preference for the consumption of information in video format.

Table 6 - Content consumption

\begin{tabular}{|c|c|c|c|c|c|c|c|}
\hline & & -1 & 0 & 1 & 2 & 3 & 4 \\
\hline \multicolumn{8}{|l|}{ Text } \\
\hline \multirow{2}{*}{ Information - News/ Opinion Articles/etc. } & Freq. & 0 & 1 & 12 & 26 & 50 & 31 \\
\hline & $\%$ & $0,0 \%$ & $0,8 \%$ & $10,0 \%$ & $21,7 \%$ & $41,7 \%$ & $25,8 \%$ \\
\hline \multirow{2}{*}{ Books } & Freq. & 2 & 20 & 44 & 33 & 17 & 4 \\
\hline & $\%$ & $1,7 \%$ & $16,7 \%$ & $36,7 \%$ & $27,5 \%$ & $14,2 \%$ & $3,3 \%$ \\
\hline \multirow{2}{*}{ Posts on social networks } & Freq. & 4 & 2 & 6 & 19 & 31 & 58 \\
\hline & $\%$ & $3,3 \%$ & $1,7 \%$ & $5,0 \%$ & $15,8 \%$ & $25,8 \%$ & $48,3 \%$ \\
\hline \multicolumn{8}{|l|}{ Image } \\
\hline \multirow{2}{*}{ Photographs } & Freq. & 1 & 0 & 4 & 14 & 42 & 59 \\
\hline & $\%$ & $0,8 \%$ & $0,0 \%$ & $3,3 \%$ & $11,7 \%$ & $35,0 \%$ & $49,2 \%$ \\
\hline \multirow{2}{*}{ Memes } & Freq. & 5 & 7 & 18 & 24 & 26 & 40 \\
\hline & $\%$ & $4,2 \%$ & $5,8 \%$ & $15,0 \%$ & $20,0 \%$ & $21,7 \%$ & $33,3 \%$ \\
\hline \multicolumn{8}{|l|}{\begin{tabular}{|l|} 
Audio \\
\end{tabular}} \\
\hline \multirow{2}{*}{ Informative content } & Freq. & 5 & 5 & 14 & 28 & 45 & 23 \\
\hline & $\%$ & $4,2 \%$ & $4,2 \%$ & $11,7 \%$ & $23,3 \%$ & $37,5 \%$ & $19,2 \%$ \\
\hline \multirow{2}{*}{ Entertainment content } & Freq. & 3 & 3 & 3 & 16 & 44 & 51 \\
\hline & $\%$ & $2,5 \%$ & $2,5 \%$ & $2,5 \%$ & $13,3 \%$ & $36,7 \%$ & $42,5 \%$ \\
\hline \multirow{2}{*}{ Music } & Freq. & 16 & 0 & 0 & 5 & 28 & 71 \\
\hline & $\%$ & $13,3 \%$ & $0,0 \%$ & $0,0 \%$ & $4,2 \%$ & $23,3 \%$ & $59,2 \%$ \\
\hline \multicolumn{8}{|l|}{\begin{tabular}{|l} 
Video \\
\end{tabular}} \\
\hline \multirow{2}{*}{ Films/Series/Documentaries } & Freq. & 0 & 1 & 4 & 13 & 63 & 39 \\
\hline & $\%$ & $0,0 \%$ & $0,8 \%$ & $3,3 \%$ & $10,8 \%$ & $52,5 \%$ & $32,5 \%$ \\
\hline \multirow{2}{*}{ Information } & Freq. & 6 & 2 & 9 & 21 & 60 & 22 \\
\hline & $\%$ & $5,0 \%$ & $1,7 \%$ & $7,5 \%$ & $17,5 \%$ & $50,0 \%$ & $18,3 \%$ \\
\hline \multirow{2}{*}{ Video clip } & Freq. & 1 & 0 & 13 & 15 & 55 & 36 \\
\hline & $\%$ & $0,8 \%$ & $0,0 \%$ & $10,8 \%$ & $12,5 \%$ & $45,8 \%$ & $30,0 \%$ \\
\hline \multirow{2}{*}{ Advertisement } & Freq. & 3 & 14 & 26 & 24 & 36 & 17 \\
\hline & $\%$ & $2,5 \%$ & $11,7 \%$ & $21,7 \%$ & $20,0 \%$ & $30,0 \%$ & $14,2 \%$ \\
\hline \multirow{2}{*}{ Comedy sketches } & Freq. & 0 & 5 & 12 & 30 & 51 & 22 \\
\hline & $\%$ & $0,0 \%$ & $4,2 \%$ & $10,0 \%$ & $25,0 \%$ & $42,5 \%$ & $18,3 \%$ \\
\hline \multirow{2}{*}{ Short animations } & Freq. & 2 & 3 & 30 & 20 & 44 & 21 \\
\hline & $\%$ & $1,7 \%$ & $2,5 \%$ & $25,0 \%$ & $16,7 \%$ & $36,7 \%$ & $17,5 \%$ \\
\hline \multirow{2}{*}{ Sports (football matches, etc.) } & Freq. & 0 & 27 & 35 & 21 & 22 & 15 \\
\hline & $\%$ & $0,0 \%$ & $22,5 \%$ & $29,2 \%$ & $17,5 \%$ & $18,3 \%$ & $12,5 \%$ \\
\hline
\end{tabular}

-1: Lacking; 0: Never; 1: Rarely; 2: Some times per month; 3: Some times per week; 4: Every day

The analysis of the previous table also allows to conclude that reading books through the Internet is an activity that a great part of the students does rarely (36.7\%). There is also a rare consumption of video content linked to sports (football matches, etc.) (29.2\%).

\section{FINAL CONSIDERATIONS}

In reality, the Internet has assumed a preponderant role in the daily events of individuals, mainly in younger people. The consumption of media content in digital format has become a common practice, enhanced by the increase of tools and devices that can support its reproduction/dissemination. Whether it is informative content, entertainment content or social content, consumers are being given access - increasingly benefiting from the growing Internet access speed - anytime, anywhere.

In this study, carried out within the scope of the CI\&DETS 0014 project, the students' online consumption habits of the School of Education of the Polytechnic Institute of Viseu were analyzed and the preliminary 
data presented a high percentage on the topic of frequency of Internet access, indicating that $95.8 \%$ of surveyed students access online platforms daily. The most frequently consumed content on the internet is music $(59.2 \%)$, photographs $(49.2 \%)$ and posts in social networks $(48.3 \%)$. The majority of respondents reported viewing video content some times a week in the form of films/series/documentaries (52.5\%) and information (50.0\%). Moreover, the consumption of contents held on a weekly access basis favors the video format in detriment of the textual and audio formats. Lastly, there is a weak participation on behalf of students to what concerns reading books through the Internet (36.7\%) and viewing videos related to sports $(29.2 \%)$.

The results obtained are in line with those of the INE Survey on the Use of Information and Communication Technologies by Families, carried out in 2016 by INE, which show the students' widespread use of the Internet. According to the data presented, the report "The new dynamic of audio-visual consumption in Portugal" by ERC (2016) also highlights that video consumption is a significant practice - carried out by over half of the sample, within the scope of consumption habits of online content.

\section{ACKNOWLEDGMENT}

This work is financed by national funds through FCT - Fundação para a Ciência e Tecnologia, I.P., under the project UID/Multi/04016/2016. Furthermore, we would like to thank the Instituto Politécnico de Viseu and CI\&DETS for their support.

\section{REFERENCE LIST}

Almeida, A. T., \& Gouveia, P. (2016). Ciberbullying, o papel dos pais, da família e da escola. In Ivone Patrão e Daniel Sampaio (Coord.), Dependências Online - O poder das tecnologias. Lisboa: Pactor, 75-96.

Autoridade Nacional de Comunicações (ANACOM) (2016). O consumidor de comunicações eletrónicas 2015, 2016 january. Available at https://www.anacom.pt/streaming/ConsumidorComunicacoesEletronicas.pdf?contentld=1380856\&field $=$ ATTACHED_FILE.

Bracy, C., Bevill, S., \& Roach, T. D. (2010). The millennial generation: recommendations for overcoming teaching challenges. Proceedings of the Allied Academies International Conference. Academy of Educational Leadership, Arden, 21-25.

Cardoso, G., Espanha, R., \& Lapa, T. (2009). Do quarto de dormir para o mundo. Jovens e media em Portugal. Lisboa: Âncora Editora.

Durães, P. (2017). Mobile representou $41 \%$ dos acessos a sites em Portugal no mês de março. In meios \& Publicidade, May $4^{\text {th }}$, 2017. Available at http://www.meiosepublicidade.pt/2017/05/mobile-representou41-dos-acessos-sites-portugal-no-mes-marco/.

Instituto Nacional de Estatística (INE) (2016). Inquérito à Utilização de Tecnologias da Informação e da Comunicação pelas Famílias. Available at

https://www.ine.pt/xportal/xmain?xpid=INE\&xpgid=ine_destaques\&DESTAQUESdest_boui=25025469 8\&DESTAQUESmodo $=2$.

Internet World Stats (IWS). (2017). Usage and Population Statistics. Available at http://www.internetworldstats.com/stats.htm.

Mcluhan, M. (1964). Understanding Media: The Extension of Man. New York: Signet Books.

Patrão, I. \& Hubert, P. (2016). Os comportamentos e as preferências online dos jovens portugueses: o jogo online e ar redes sociais. In Ivone Patrão e Daniel Sampaio (Coord.), Dependências Online - O poder das tecnologias. Lisboa: Pactor, 97-116.

Patrão, I. \& Sampaio, D. (2016). Dependências Online - O poder das tecnologias. Lisboa: Pactor.

Ponte, C. (2016). Um desafio dos tempos modernos: A Internet e as novas gerações. In Ivone P., and Daniel S. (Coord.), Dependências Online - O poder das tecnologias. Lisboa: Pactor, 1-18. 